\title{
Is the blue tit falling into an ecological trap in Argentine ant invaded forests?
}

\author{
David Estany-Tigerström • Josep Maria Bas • \\ Miguel Clavero $\cdot$ Pere Pons
}

\begin{abstract}
Because insectivorous birds must evaluate resources for reproduction before settling into a breeding habitat, they can fall into an ecological trap if informative cues about habitat suitability become dissociated from their actual yield. Given their potential to affect ecological networks, invasive ant species are potential candidates for triggering such ecological traps. We combined observational and experimental approaches to examine whether the variation in food supply for nestlings resulting from the invasion of the Argentine ant, Linepithema humile, had any influence on the breeding ecology of the blue tit, Cyanistes caeruleus, an insectivorous foliage-gleaner. We investigated the effects of the ant invasion on breeding performance (nesting success, clutch size, brood size and breeding success) and offspring quality (body size and condition, developmental stability and plumage colour) in replicated Mediterranean forest areas over a period of 3 years. There was no evidence that the reduction in caterpillar availability resulting from the invasion had a concurrent negative effect on the blue tit's ability to successfully rear nestlings in optimal conditions, at least as measured here. Although the raw
\end{abstract}

D. Estany-Tigerström · J. M. Bas · P. Pons $(\square)$ Departament de Ciències Ambientals, Universitat de Girona, Campus de Montilivi, 17071 Girona, Spain e-mail: pere.pons@udg.edu

M. Clavero

Department of Conservation Biology, Estación

Biológica de Doñana-CSIC, 41092 Sevilla, Spain figures suggest an increased level of nutritional stress in blue tits breeding in invaded forests, the data analyses showed no significant alterations in terms of productivity or offspring fitness. The reproductive performance of the blue tit has been shown to be remarkably resilient to the Argentine ant-mediated food shortage, either because the prey reduction following the invasion did not reach a critical threshold or because of compensatory activity by the progenitors. We cannot conclusively reject an ecological trap triggered by the ant invasion on blue tits, since neither fledgling recruitment nor the prospective survival of parents were assessed. Even though we could not confirm short-term consequences of the Argentine ant invasion on blue tit reproductive fitness, the long-term bottom-up effects of the invasion remain unknown and should not be ruled out.

Keywords Ant-bird interactions - Biological invasions · Cross-fostering - Fledgling quality · Generalized linear mixed models

\section{Introduction}

An ecological trap arises when, after a change in the environmental conditions, the settlement decisions of an individual no longer lead to the expected positive outcome associated with those decisions (Robertson and Hutto 2006). In other words, although the informative cues regarding habitat suitability are 
dissociated from their actual yield, individuals' settlement preferences remain the same, and the return obtained from the altered environment is reduced. Insectivorous birds mainly rely on vegetation structure to select nesting sites and use these cues to forecast the future resources available for their nestlings (Marshall and Cooper 2004). Consequently, insectivorous birds have to settle into their breeding habitat long before the resources for breeding are fully available and are therefore potential victims of an ecological trap.

Given their capacity to modify the natural attributes of the habitats they invade, invasive species are one of the various possible agents that can create ecological traps. Even though invasive insects may bring about certain positive effects on ecological interactions (Gandhi and Herms 2010), many of them, particularly forest herbivores and ants, alter ecosystem processes by triggering cascading effects that reverberate throughout the ecosystem (Kenis et al. 2009). Invasive ants are among the worst biological invaders and have frequently been responsible for changes in the structure and dynamics of native arthropod communities (Holway et al. 2002). The Argentine ant Linepithema humile (Mayr 1868) is a major global invasive ant species, occurring in human-modified habitats but also in natural ecosystems worldwide, where it dominates ant assemblages (Bond and Slingsby 1984). Besides displacing ground-dwelling ants and other arthropods (Human and Gordon 1997), the Argentine ant invasion also impacts on invertebrate assemblages in the canopy (Carpintero et al. 2005; Estany-Tigerström et al. 2010). The worldwide spread of the Argentine ant has been accompanied by a downward shift in its trophic position. Thus, it has switched from a carnivorous diet in its native range to a more flexible diet, consisting mostly of plantbased resources, especially honeydew produced by aphids (Order Hemiptera), in those areas where it has been introduced (Abril et al. 2007; Tillberg et al. 2007). Even so, in accordance with its trophic requirements for reproduction, the Argentine ant maintains an appetite for protein-rich foods such as arthropods, which it preys on in the invaded areas (Abril et al. 2007).

In a parallel survey (same dates, same study sites) investigating the effects of the ant invasion on the community of arboreal foliage arthropods, we detected that the availability of food resources for coexisting foliage-gleaning birds was regulated by the Argentine ant presence (Estany-Tigerström et al. 2010). The Argentine ant invasion caused the local extinction of most native ant species and reduced the diversity of arboreal foliage arthropods. In addition, the effects of the Argentine ant invasion on arthropod availability for foliage-gleaning birds were found to depend on the plant species sampled. In terms of key prey for nestlings there was a reduction in caterpillars (by almost one half of the biomass) in cork oaks Quercus suber (Linnaeus 1753) in the invaded areas compared to the uninvaded areas. In contrast, we also found that in tree heaths, Erica arborea (Linnaeus 1753), there were more spiders in invaded areas than in uninvaded areas.

Insectivorous birds and ants have important effects on the invertebrate assemblages that they feed upon (Halaj and Wise 2001), and the relative strength of these predators in regulating arthropod communities depends on the nature of the predator-prey system (Piñol et al. 2010). Co-occurring insectivorous birds and ants can be involved in a range of exploitative and interference interactions. Indeed, ant activity has been found to interfere with bird foraging ecology, nest-site selection and breeding performance (Aho et al. 1999; Haemig 1999). Optimizing food resources is essential for the blue tit Cyanistes caeruleus (Linnaeus 1758), as well as for other insectivorous songbirds, during the breeding season and a scarcity of prey therefore exposes them to a variety of negative consequences on aspects ranging from nestling development (Naef-Daenzer and Keller 1999) to breeding fitness (Nur 1984). In this sense, food availability and nutrient intake during the developmental stage can be associated with certain quality-related traits of blue tit nestlings such as body weight and size (Naef-Daenzer and Keller 1999), developmental stability (Grieco 2003) and carotenoid-based plumage coloration (Slagsvold and Lifjeld 1985). In tits (Paridae), various descriptors of nestling quality related to food availability (e.g., body size and condition, developmental stability and carotenoid-based coloration, among others) have been found to influence their chance of surviving after fledging (Naef-Daenzer et al. 2001), their fecundity (Clarke 1995), their immunocompetence (Arriero and Fargallo 2006) and their long-term ability to control parasites (Stjernman et al. 2008). The concurrence of Argentine ants and insectivorous birds can lead to both direct and indirect interactions and it is thought that the invasive ant may be impacting blue tit reproduction through two independent but non-exclusive processes. First, Argentine ants may be giving rise to a top-down effect by preying on newly-hatched nestlings. Second, by curtailing habitat suitability 
through a reduction in the food resources available for nestlings, the Argentine ant may be indirectly causing bottom-up effects on the fitness of both offspring and breeders.

Studies on the effect of invasive insect species on ecosystem processes are still rare; most publications focus on their effects on native biodiversity at population or community levels (Kenis et al. 2009). For the Argentine ant specifically, the evidence of deleterious effects of its invasion on native communities of vertebrates is scarce, ranging from population declines to disturbed ontogenic development and offspring predation (Hooper-Bui et al. 2004; Laakkonen et al. 2001; Suarez and Case 2002). A previous study in Catalonia, detected only slight differences on the abundance of various foliage-gleaning passerines attributable to the Argentine ant occurrence (Pons et al. 2010).

The main objective of the present study is to assess the impacts of the Argentine ant invasion on the reproduction of the blue tit. To this end, we used an experimentalmanipulation approach in replicated forest areas over 3 years. The study sites selected enabled us to investigate how the presence of the Argentine ant induces variation in the ecological conditions (e.g. food availability) that affect breeding performance and, consequently, reproductive fitness traits. Given that the blue tit is a foliagegleaner which feeds its young on a strictly insectivorous diet (in the uninvaded areas we studied, caterpillars constitute up to $75.1 \%$ of prey items and $82.4 \%$ of dietary biomass; unpublished results), we predicted that the reduction of prey availability for chicks raised in Argentine ant invaded areas (Estany-Tigerström et al. 2010) would hinder the blue tit's breeding performance. In this sense, we hypothesized that these short-term impacts of the Argentine ant invasion could effectively constitute the basis of an ecological trap for breeding blue tits that would be reflected in reduced nesting success, a fall in reproductive productivity or in poorer fledgling quality (i.e. lower body size or condition, lower developmental stability, or reduced expression of carotenoidbased plumage coloration).

\section{Material and methods}

Study areas

The eight study areas used were located in the Mediterranean coastal mountains of Gavarres and
Ardenya in Catalonia, in the north-eastern Iberian Peninsula (mean coordinates: $41^{\circ} 48^{\prime} \mathrm{N}, 3^{\circ} 00^{\prime} \mathrm{E}$ ). We selected four study areas in habitats that were completely invaded (i.e., where the Argentine ant is overabundant and only a few small native species coexist with it at low densities) and four in uninvaded habitats (in which only native ant species occur). The selected areas shared similar vegetation (consisting of cork oak forest with a dense understory), substrate, altitude and climate, and were geographically close to one another. This means that the presence of the Argentine ant was the main distinguishing feature between invaded and uninvaded areas. A special effort was made to adequately select interspersed invaded and uninvaded study areas in the region (see Estany-Tigerström et al. 2010; Pons et al. 2010). In each study area, we selected a transect of approximately $1,500 \mathrm{~m}$ in length. Each transect was furnished with a set of 25 blue-tit suitable, wooden nest boxes (GACO 2000 model; entrance diameter $27 \mathrm{~mm}$; interior dimensions: height, $240 \mathrm{~mm}$, base $90 \times 150 \mathrm{~mm}$ ), separated by at least $50 \mathrm{~m}$ from each other and $2 \mathrm{~m}$ from the pathway. The nest boxes were strategically placed at least $150 \mathrm{~m}$ away from the current invasion front in order to ensure that the blue tits were foraging exclusively in either invaded or uninvaded areas (Naef-Daenzer 2000). The nest boxes were hung from tree branches at a height of 2-4 m. We removed old nest material every year before the onset of breeding.

Blue tit data collection

The breeding blue tit population was studied from 2005 to 2007 . Nest boxes were routinely checked at least every 3 days during nesting season. For each brood, we compiled data on nest construction, the date egg laying began (hereafter laying date), clutch size (number of eggs of a complete clutch), hatching date and the number of hatchlings. Hatching date was estimated for complete clutches, assuming synchronic hatching and one egg laid per day for those broods whose hatching date could not be determined visually. Occupied nests were considered successful if at least one nestling fledged. Nests were considered preyed upon by vertebrates if eggs or nestlings disappeared before they were old enough to fledge. These nests were excluded when analyzing nest success, as we regarded predation and Argentine ant invasion as independent effects (cf. below). At day 14 of the 
nestling cycle (hatch day $=$ day 0 ), when chicks are considered fully grown (Bjorklund 1996), we recorded the brood size (number of fledglings), the fledglings' weight $( \pm 0.1 \mathrm{~g})$ and the length of the right tarsus ( $\pm 0.01 \mathrm{~mm}$; dial calliper). The left tarsus length and carotenoid-based plumage coloration were also measured for 2006 and 2007 fledglings. All measurements of fledglings were carried out by the same person (D.E.T.) and were highly repeatable (Lessells and Boag 1987).

Given the difficulty in identifying a single index of health that summarizes all aspects of juvenile quality (Blem 1990), a variety of indices potentially affected by food supplies were considered. Tarsus length is a putative index of growth performance, used as a predictor of avian body size and fledgling quality (e.g. Blondel et al. 1998). The body condition of fledglings was estimated by including tarsus length as a covariate in the body mass analyses (Garcia-Berthou 2001). We assessed the nestlings' developmental stability through the fluctuating asymmetry of tarsus length, a common estimate of developmental stability (Clarke 1995), computed as the absolute difference between right and left tarsus. Fluctuating asymmetry was not correlated with tarsus length (Pearson $r=0.01$, $n=786, P=0.708$ ); therefore no size correction of the asymmetry index was applied. The fledglings' breast plumage coloration was measured in triplicate (the mean being used in the analyses) using a MINOLTA CR400 portable Chroma Meter (Konica Minolta Sensing Europe B.V., Nieuwegein, Netherlands) following Figuerola et al. (1999). Plumage colour was characterized in accordance with the LCH (Lightness, Chroma, Hue) colour system. The chroma coordinate is a measure of the spectral purity or saturation of a colour. It is expressed as the percentage of colour dilution, with white varying from 0 (grey) to 100 (full saturation). The hue coordinate refers to the spectral location of the dominant component of the light in a $360^{\circ}$ circular array of the visible wavelengths, i.e. the ordinary meaning of colour $\left(90^{\circ}\right.$ : yellow; $120^{\circ}$ : green). A positive association between yellow breast chroma and body condition has been described for tits (Johnsen et al. 2003), while hue has been found to reflect the carotenoid concentration allocated to feathers (Saks et al. 2003a).

A total of 364 blue tit broods (1,248 and 1,194 nestlings from 191 nests in invaded areas and 173 nests in uninvaded areas, respectively) were monitored during 2005-2007. The analyses of nest occupation and success referred to the nests available for blue tits (268 in invaded areas and 279 in uninvaded areas) once we had excluded those nest boxes occupied by co-occurring bird species, i.e. Parus major (31 in invaded areas, 21 in uninvaded areas) and Passer montanus (1 in an uninvaded area). Breeding analyses were limited to broods with at least one young fledged (163 in invaded areas, 131 in uninvaded areas). Twenty clutches were unhatched, and 3 clutches (28 eggs) as well as 32 broods (230 nestlings) disappeared before day 14 and were regarded as having been preyed upon. Additionally, complete brood mortality (nestlings found dead in the nest) occurred in 15 nests (98 nestlings). No significant differences were found in brood mortality between invaded and uninvaded areas $[3.0 \% \pm 1.3$ (168) vs. $7.09 \% \pm 2.2$ (141); binomial GLMM: $\mathrm{z}=1.628$, $P=0.104]$, and no nest predation by Argentine ants was found. Neither did we find differences in mortality between cross-fostered or unmanipulated nestlings in the cross-fostering experiment (cf. below) $[0.92 \% \pm$ 0.65 (217) vs. $1.40 \% \pm 0.81$ (214); Binomial GLMM: $\mathrm{z}=1.462, P=0.644]$, indicating that our results were not significantly biased by differential mortality. Analyses on fledgling condition were limited to fledglings reared in unmanipulated nests with at least one young fledged (756 and 702 fledglings from 120 nests in invaded areas and 99 nests in uninvaded areas, respectively). Developmental stability and colour analyses were restricted to the 2006-07 data from unmanipulated nests ( 383 and 416 fledglings from 62 nests in invaded areas and 57 nests in uninvaded areas, respectively).

\section{Cross-fostering}

Since the indices of condition used to assess nestling growth and development are genetically and environmentally determined, we conducted a cross-fostering experiment to accurately evaluate the invasion effects on fledgling quality while accounting for the heritable component of the phenotypic variation. In this experiment, we created dyads by pairing nests from invaded and uninvaded areas and interchanging approximately half of the brood between them. Dyads were selected according to hatching date ( \pm 0 days) and clutch size ( \pm 2 nestlings), maximizing a full cross-over design between invaded and uninvaded transects. Shortly 
after hatching (day 2), the same number of hatchlings were swapped between the two nests, so that brood size remained unaltered and a balanced number of original and foster chicks were raised together in the resulting crossed broods. In order to avoid skewing body weight in the dyads in either direction, the nestlings were ranked according to weight within their origin brood and alternatively assigned to be either cross-fostered or remain in the source nest. Each nestling was individually indentified by clipping the tip of a claw (day 2) and ringing (day 10). Fledgling weight, right and left tarsus lengths and plumage colour were measured at day 14. All the invaded and uninvaded transects were fully crossed in the experimental dyads created (each and every invaded transect was crossed with all four uninvaded transects, and vice versa), which involved 257 and 225 nestlings from 36 and 28 nests in 2006 and 2007 respectively.

\section{Statistical analyses}

We used univariate generalized linear mixed models (GLMMs) to sequentially test the effect of the Argentine ant invasion factor (invaded, uninvaded) on a set of dependent variables based on either (1) nest data ('nest occupation', 'laying date', 'nest success', 'clutch size', 'hatching success' (\% of hatchlings to eggs laid), 'brood size', 'fledging success' (\% of fledglings to hatchlings), 'breeding success' ( $\%$ of fledglings to eggs laid), 'within-nest body size difference' and 'within-nest body weight difference') or (2) fledgling measurements ('tarsus length', 'fluctuating asymmetry', 'body condition', and 'chroma' and 'hue' of breast feathers). Tarsus length and body weight were centred by subtracting the population mean to avoid meaningless interpretation of the models' intercepts (Zuur et al. 2009). 'Within-nest body weight difference' was not normally distributed and was therefore $\log$ transformed. In the GLMMs for nest variables, we included the random terms 'year' and 'transect' nested in 'invasion' to account for yearly variation and the hierarchical structure of our experimental design (Crawley 2007). When analyzing fledgling variables, the random model was extended with 'nest' nested in 'transect', and 'transect' nested in 'invasion', to account for non-independence of data on siblings, and the interaction between 'nest' and 'year' to cope with the uncertainty as to which adults are breeding in each nest box every year. In the analyses evaluating cross-fostering data, the GLMMs allowed us to account for the genetic and genetic-environment interaction components of the fledglings' phenotypic variation by extending the random model with the factors 'nest of rearing', 'dyad' and 'nest of origin'. The term 'dyad' accounted for any differences in fledgling size and condition between pairs of nests (e.g. due to differential parental quality, food availability, etc.). The term 'nest of origin' nested in 'dyad' accounted for genetic differences (i.e. the variation attributable to genetic transmission, including premanipulation maternal effects and variance prior to the exchange of nestlings (Laaksonen et al. 2008). The interaction between 'invasion' and 'dyad' accounted for possible differences in the effects of invasion between dyads. Genotype-environment interaction was controlled by including the interaction between 'invasion' and 'nest of origin' nested in 'dyad'.

The Argentine ant invasion ('invasion') was the factor of principal interest and was therefore always included as a fixed term in the models. Fixed effects also incorporated different sets of controlling variables in the models (as main effects and first order interaction with 'invasion'), thought to affect breeding performance in passerines, in order to reduce error variation (Gelman and Hill 2007). When testing the invasion effects on variables of breeding output ('clutch size', 'hatching success', 'brood size', 'fledging success' and 'breeding success') the models included 'laying date' and 'clutch size' as controlling variables (except in the analyses of 'clutch size' and 'hatching success'). When analyzing the invasion effects on fledgling quality ('within-nest body size difference', 'within-nest body weight difference', 'tarsus length', 'fluctuating asymmetry', 'body condition','chroma' and 'hue') the models included 'laying date' and 'brood size' as controlling variables.

The structure of the minimum adequate model (MAM) was decided under the likelihood ratio (LR) test criterion; first by evaluating the optimal random structure through a stepwise deletion of random terms from a fully saturated model and second, given the optimal random structure selected, by deleting nonsignificant first order interactions of fixed terms. Nonsignificant interaction terms are not presented in the results. Random terms accounting for yearly variation and the hierarchical structure of the experimental design were always retained in the models (Hurlbert 1984). In the comparison of nested models, we used restricted maximum likelihood (REML) when assessing the optimal random structure, 
and maximum likelihood when comparing models with different fixed effects. REML was also used to compute the estimates of coefficients for the MAMs achieved (Zuur et al. 2009). Normality and homoscedasticity were checked by visually inspecting the plots of residuals against fitted values. Binary variables (such as 'nest success') and proportions (such as 'hatching success') were analyzed using a logit link function and binomial distribution. When analyzing discrete variables (such as 'clutch size'), we used a logit link function and Poisson distribution. Continuous variables (such as 'tarsus length') were analyzed using an identity link function and Gaussian distribution by fitting linear mixed models.

Additionally, we calculated the effect size (as the difference of the means of invaded transects and those of uninvaded transects) for a selection of standardized variables explaining reproductive fitness parameters thought to be influenced by the Argentine ant invasion (Fig. 1). In order to homogenize the direction of the effect, the sign of the scores for effect sizes were changed for variables inversely associated to an enhancement of reproductive fitness. Hence 'withinnest body size difference', 'within-nest body weight difference' and 'fluctuating asymmetry' became 'within-nest body size homogeneity', 'within-nest body weight homogeneity' and 'developmental stability', respectively. With the aim of interpreting the overall impact of Argentine ant invasion on blue tit reproduction, the mean scores for effect sizes were compared to 0 with a One-Sample Student's $t$ test.

The models and data were analyzed using $\mathrm{R}$ statistical package 2.10.1 (R Development Core Team 2009). The parameters in the GLMM were obtained using the lme $4 \mathrm{R}$ package (Bates and Maechler 2010), except for the GLMM analyzing continuous variables, for which P-values were estimated based on Markovchain Monte Carlo (MCMC) sampling (50,000 iterations) by means of pvals.fnc function in the languageR package (Baayen 2010).

\section{Results}

\section{Effect sizes}

Although the scores for standardized effect sizes showed a general trend (Fig. 1) that suggests that the reproductive environment for blue tits in Argentine ant invaded areas is disadvantageous with respect to that of uninvaded areas, the scores were found to be not significantly different from 0 in the comparison test (mean $=0.059$; One Sample $t$ test; $t=1.423$, $d f=11, p$ value $=0.82)$,

\section{Breeding}

Blue tits started to breed roughly at the same time in invaded and uninvaded areas and occupied a similar amount of available nest boxes. Comparisons did not reveal significant differences in reproductive output between pairs breeding in invaded and those breeding in uninvaded areas in terms of nest success, clutch size, brood size, hatching success, fledging success and breeding success. Broods throughout the invaded and uninvaded areas were found to be evenly homogeneous both in terms of nestling size and weight (Table 1).

In both invaded and uninvaded areas, the blue tit fledglings achieved similar sizes and body condition, similar nestling developmental stability (fluctuating asymmetry) and similar carotenoid-based plumage coloration in terms of chroma and hue (Table 2).

\section{Cross-fostering}

The weight of nestlings involved in the cross-fostering experiment were not significantly different between broods in invaded and uninvaded areas immediately before manipulation (mean nestling body mass: $2.04 \mathrm{~g} \pm 0.04$ vs. $2.06 \mathrm{~g} \pm 0.04$, paired $t$-tests controlling for false discovery rate: $p$ value $\geq 0.40$ ) nor immediately after manipulation (mean nestling body mass: $2.07 \mathrm{~g} \pm 0.04$ vs. $2.04 \mathrm{~g} \pm 0.04, p$ value $\geq 0.44$ ). In other words, we detected no experimental bias that may have arisen if there had been differences in initial body mass between broods from the two areas. Tarsus length and weight for fledglings reared in the original nest were compared with those of their full siblings raised in non-original nests to test whether swapping the fledglings had any effect on fledgling quality, but no significant differences were found between the two groups (paired $t$-tests controlling for false discovery rate: $p$ value $\geq 0.11$ for tarsus length and $p$ value $\geq 0.30$ for weight comparisons). Hence, the interchange of young did not affect their quality at fledging.

The nests involved in the cross-fostering experiment produced similar results, in terms of the effects of invasion, to those produced by the rest of the nests. After controlling for variation due to genetic causes in 




Fig. 1 Magnitude and direction of Argentine ant invasion standardized effect sizes, obtained by comparing reproductive fitness related variables of blue tit pairs breeding in uninvaded and in invaded areas. Effect sizes were calculated for each standardized variable by subtracting the mean of uninvaded

fledgling phenotypes, invasion effects were not detected either on fledgling size or their condition. Again, there were no significant differences in developmental stability between fledglings reared in invaded areas and those reared in uninvaded ones and neither were there any significant differences in saturation (chroma) and yellowness (hue) of carotenoid-based plumage. No model analyzing cross-fostering data retained in the optimal random structure either the term 'dyad' or the two interactions of 'invasion' with 'dyad' and with 'nest of origin' (nested in 'dyad') when evaluated under LR test criterion. The exclusion of the term 'dyad' suggests the differences in nestling growth between pairs of nests is not relevant in the models. Non-significant interaction between 'invasion' and 'dyad' suggests the invasion effects did not differ between dyads. There was no evidence for genotype-environment interaction in fledgling quality (i.e., non-significant interaction of the terms 'invasion'*'nest of origin' ('dyad')), indicating that chicks from different families did not differ in their response to the 'invasion' factor (Table 3).

\section{Discussion}

Even though the raw data compiled here suggests that, for blue tits, cork oak Mediterranean forests that from the mean of invaded transects. Positive values indicate a worse reproductive performance in invaded areas, whilst negative values indicate the opposite. Dots and lines show the standardized effect size $\pm 95 \%$ confidence intervals

remain uninvaded by the Argentine ant are better for breeding, the main effect of the invasion was not found to be significant for any of the variables explaining breeding performance. The bulk of variables evaluated along with the analysis of the standardized effect sizes, albeit non-significant, indicate that areas invaded by the Argentine ant are a disadvantageous reproductive environment for blue tit nestlings since, in invaded areas, blue tits tended to lay smaller clutches, to achieve lower fledging success, and to grow smaller and lighter fledglings bearing slightly yellower and duller plumage. In contrast, a few variables (nest success, hatching success and sibling size homogeneity) produced results that were at odds with the majority of the features analyzed, although again nonsignificant, which could be indicating that conditions in invaded areas were actually better for reproduction (Fig. 1).

The nesting success of blue tits was similar in invaded and uninvaded areas. Although Argentine ant workers were found wandering and feeding on dead nestlings at three nests, as were native ants Crematogaster scutellaris (Olivier 1792) at two nests, they were never observed attacking living nestlings. Thus, any nest failures could not be directly attributed to the Argentine ant. Neither does the invasive Argentine ant appear to influence nest site selection, given that 


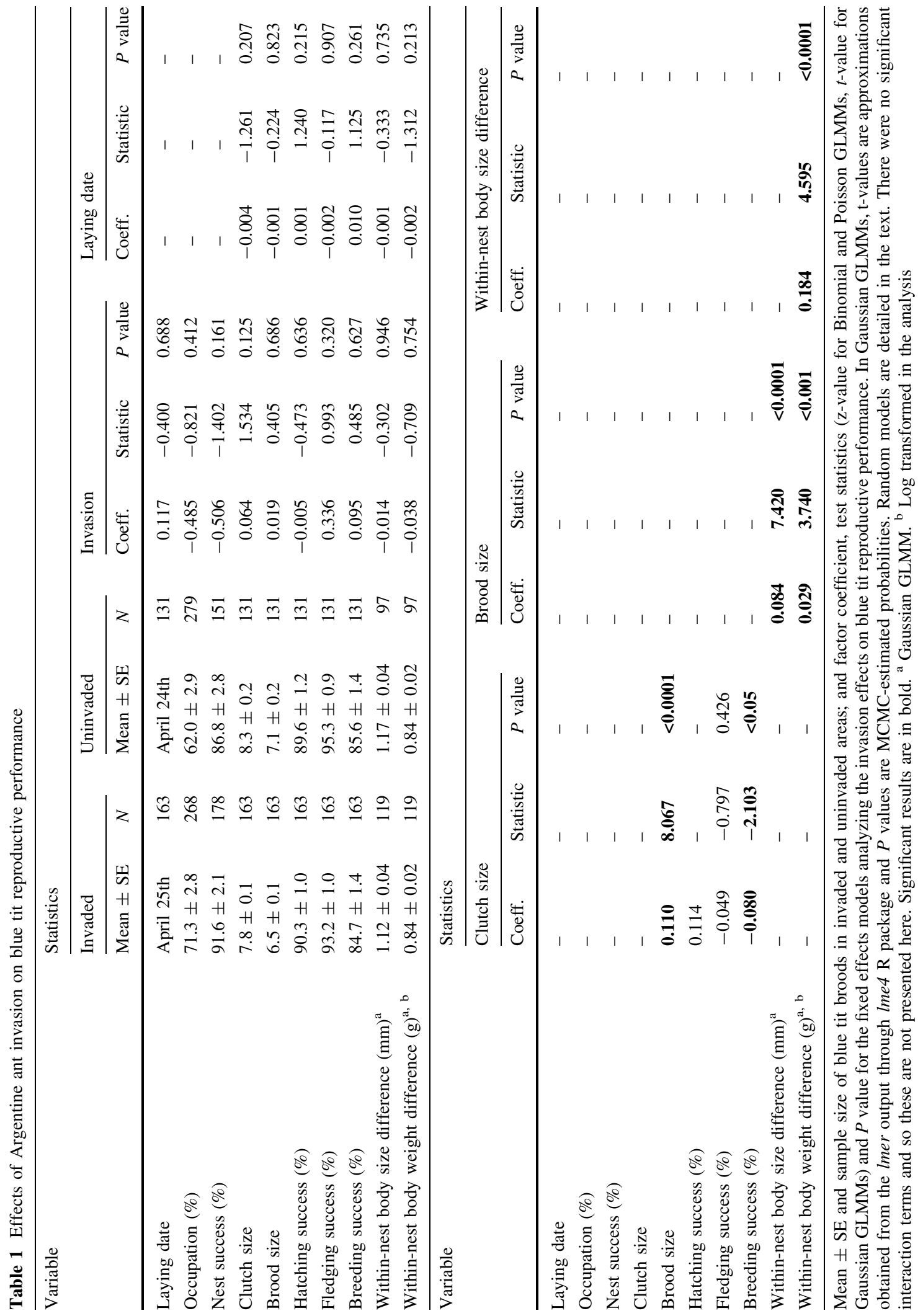


occupation rates of available nest boxes were similar in invaded and uninvaded transects. Our results are consistent with previous studies into the impact of the Argentine ant on avian nesting success since, relative to other causes of nest failure, the Argentine ant is not a serious direct menace to bird nests. Hooper-Bui et al. (2004) reported Argentine ants occasionally killing least tern chicks Sterna antillarum and Suarez et al. (2005) found that only a small percentage $(<2 \%)$ of nest failures of the dark-eyed junco Junco hyemalis, were directly attributable to the invading Argentine ant. Our findings suggest that, relative to co-occurring native ants, the Argentine ant is not a serious predatory threat to blue tit nests.

The minor, non significant differences detected in the blue tit's breeding and offspring parameters could indicate that, in the areas studied, the reduction in caterpillar availability in cork oaks of invaded forests (Estany-Tigerström et al. 2010) may not have surpassed the critical threshold required to trigger falls in reproduction productivity and/or to affect the reproductive behaviour or fledgling condition and growth. Our results are consistent with those provided by Marshall et al. (2002) in a study assessing the effects of an experimental reduction in caterpillars on the breeding ecology of the red-eyed vireos Vireo olivaceus. According to their findings, the food shortfall did not lead to reduced breeding performance nor did it produce a reduction in offspring condition. Restrictions other than food availability may play a more significant role in limiting blue tit reproduction in the areas studied. Given the high percentage of occupancy registered from the beginning of the study (the pooled nest box occupation in invaded and uninvaded areas is as follows: 61.3, 63.6 and $75.3 \%$ in 2005, 2006 and 2007 respectively), one possible limitation could be the availability of natural holes for nesting. For breeding passerines, egg laying date and clutch size are changeable demographic traits that may be adjusted prior to hatching in order to match reproductive investment to environmental constraints with the aim of maximizing the fitness of breeders and offspring. When choosing a habitat, blue tits mostly rely on structural cues-such as vegetation phenology (e.g. Bourgault et al. 2010)—as indicators of future breeding conditions and, since changes in arthropod availability resulting from Argentine ant invasion are not associated with habitat structure changes, blue tits breeding in invaded areas are not thought to modify their laying date with respect to their counterparts in uninvaded areas. Nevertheless, experimental supplemental feeding has revealed that, to some extent, clutch initiation dates may be influenced by food availability (e.g. Meijer and Drent 1999; although see also Svensson and Nilsson 1995). The similarity in laying dates in invaded and uninvaded areas suggest that, at worst, the differences detected in territory quality do not reach the decisive threshold needed to set off an advancement in the timing of reproduction.

In addition to shaping reproductive phenology, food availability may have an effect on breeding productivity. Along with its obvious determining role in productivity during the chick-rearing period, food availability may also influence clutch size during egg production. However, food-supplementation experiments in tits have produced contradictory results, with some having found a positive association between supplementation and clutch size (e.g. Nager et al. 1997) while others have found no effect (e.g. Svensson and Nilsson 1995) and there is even one case of a negative association being found (Harrison et al. 2010). Protein availability has been suggested as a main reason for the relationship between food availability and reproductive investment (Jones and Ward 1976; but see also Nager et al. 1997; Ramsay and Houston 1998). The fact that blue tit clutch sizes were similar in invaded and uninvaded areas suggest that specific nutrient requirements are satisfied even in apparently lower quality habitats such as those of the invaded areas.

On the other hand, blue tit parents are capable of coping with changing feeding scenarios during the breeding season by adjusting their foraging behaviour in order to fulfil the requirements of the brood (GarciaNavas and Sanz 2010). Thus, the impact on blue tit nestlings from a reduction in caterpillar availability in the cork oaks caused by the invasive ant are likely to be cancelled out by a change in the nestlings' diet, greater provisioning effort by the parents or changes in foraging strategies (e.g. foraging patch selection). These strategies are by no means mutually exclusive and may be put into practice at the same time. Even though caterpillars are the main source of food for blue tit nestlings, their prey can also include alternative, lower-quality arboreal arthropods [mainly spiders, but also grasshoppers and coleopterans among other taxa (Banbura et al. 1994; Cramp and Perrins 1998)]. The blue tit's preference for caterpillars when it comes to 
feeding their nestlings is based on their high abundance during the nestling stage and their high nutrient and water content (Eeva et al. 2010; Zandt 1997); furthermore, the nestlings find them more palatable and easier to swallow (Banbura et al. 1999). Changes in diet to less preferred prey have been observed in blue tits breeding in suboptimal conditions (Blondel et al. 1991; Garcia-Navas and Sanz 2011). If chicks in invaded areas were fed with a higher proportion of lower-quality prey, this diet should still provide the nutrients required to produce optimal structural growth in nestlings and ensure breeding success. However, given that caterpillars are the main source of dietary carotenes in Paridae (Slagsvold and Lifjeld 1985), fewer caterpillars in their diet could explain the apparently reduced expression of carotenoid-based plumage coloration in fledglings from invaded areas. Alternatively, or at the same time, blue tit parents, by working more, are able to compensate for a lower availability of high quality prey for their offspring (Tremblay et al. 2005; but see also Banbura et al. 2004). In the invaded areas studied here, the reduction in the availability of arthropods for the nestlings of foliage gleaners was principally observed in the upper canopy layers (i.e., the cork oaks), and corresponded mainly to a reduction in the number and biomass of caterpillars (Estany-Tigerström et al. 2010).

Intermediate vegetation layers (i.e., tree heaths) showed no negative effects of invasion in terms of arthropod biomass and, in fact, there was a greater abundance of spiders. Despite the blue tit's preference for using tree canopies as foraging sites (Cramp and Perrins 1998), variations in arthropod availability affects the tits' selection of foraging substrate in mixed woodlands (Illera and Atienza 1995). Thus, by changing their foraging substrate to intermediate vegetation in invaded forests, blue tits can benefit from these greater supplies to feed their nestlings. By altering food density and quality, studies into the optimal foraging strategies of passerines have demonstrated the existence of a trade-off between the risk of predation and foraging far from cover (Schneider 1984; Slotow and Paxinos 1997) and that a reduction in the quality of nutrients available in foraging sites under better cover results in an increased use of more exposed sites (Allen and Harper 2000). Thus, in invaded areas, the increased predation risk for parents coming down from their preferred strata of the canopy to the shrubs may be counterbalanced by the benefits they gain in providing for their offspring.

We cannot conclusively demonstrate that an ecological trap is being set for blue tits reproducing in Argentine ant invaded cork oak woods; nevertheless, we cannot definitively reject the hypothesis, either. Although we failed here to prove direct short-term effects of the invasion on blue tit reproduction in terms of productivity and offspring condition, longer-term effects on the prospective survival of parents or the success in adulthood of chicks reared in invaded habitats cannot be ruled out. Parental survival can be reduced by a higher energy expenditure on foraging and feeding offspring (Nur 1984; Tinbergen et al. 1985), as is possibly the case in invaded areas. Changes in diet to poor quality foods in order to satisfy the nestlings' energy demands may fail to provide the nutrients that are essential for optimal development and may therefore impact upon basic fitness-related traits in adulthood. Examples of such traits found to have been influenced by nutrients received during early development include adult ornamental coloration (McGraw et al. 2005), immunocompetence (Saks et al. 2003b), adult exploratory and foraging behaviours and physiological condition (Krause et al. 2009) and even the development of optimal cognitive functions essential for acquiring foraging behaviour and competitive performance (Arnold et al. 2007). However, we were not able to evaluate any such long-term effects and it remains an interesting challenge for future work.

As far as we are aware, apart from sporadic predation upon chicks (Hooper-Bui et al. 2004), the impacts of Argentine ant invasions on vertebrates have only been demonstrated for the coast horned lizard Phrynosoma coronatum (Suarez and Case 2002) and the Crawford's gray shrew Notiosorex crawfordi (Laakkonen et al. 2001). The coast horned lizard feeds almost exclusively on ants and the displacement of native ants following the invasion is thought to cause a decrease in the growth rate in juveniles and possibly the decline of natural populations (Suarez and Case 2002). The presence of Argentine ant colonies in highly fragmented and urbanized habitats was found to have strong negative impact on the abundance of Crawford's gray shrew (Laakkonen et al. 2001). The absence of short-term effects from the Argentine ant invasion on blue tit reproduction does not definitively indicate that the impacts of the invasion on 


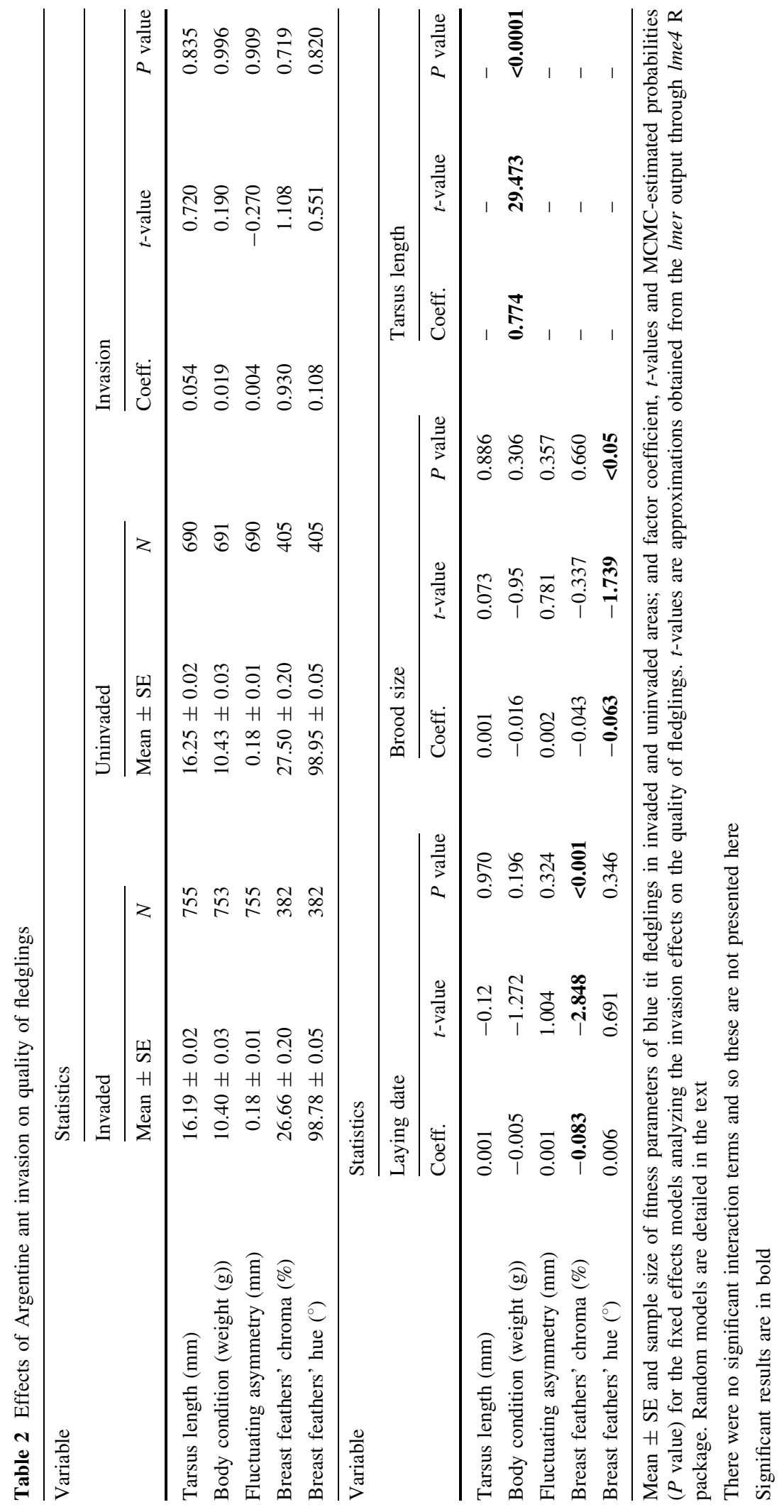




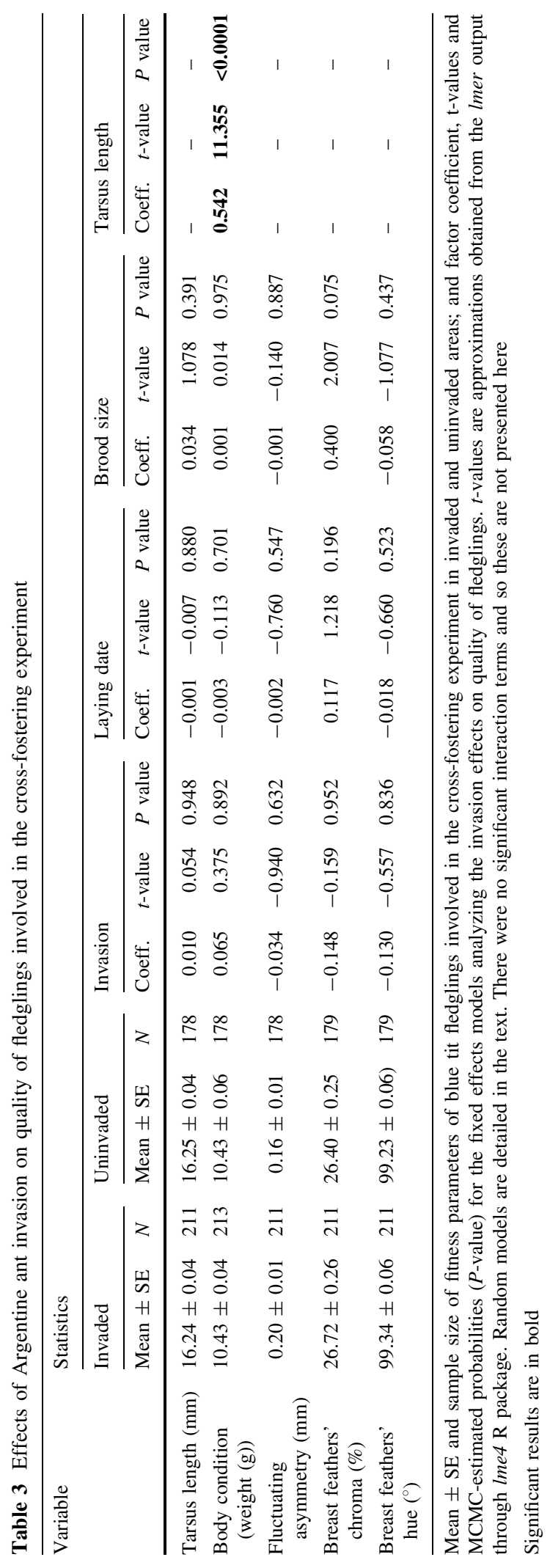


invertebrate assemblages are not spreading through the trophic web. Habitat use by blue tits and Argentine ants do not completely overlap and they only interact directly at tree canopy level, where the birds build nests and forage and where the ants tend colonies of honeydew-producing aphids (Abril et al. 2007). The Argentine ant is a soil-nesting species, and the most intense interactions may arise at ground level, where the effects of the invasion may be at their greatest. In order to further investigate the transversality of the invasion effects and their impact on vertebrates, and in addition to evaluating any possible long-term effects of the invasion on blue tit adults, attempts should be made to study more closely the performance of ground-foraging insectivores or even specialized antfeeders. Suitable candidates for such studies in the Mediterranean Basin would include shrews, reptiles, amphibians and certain ground-foraging, ant-eating birds such as the common nightingale Luscinia megarhynchos which tended to be less abundant in the areas invaded by the Argentine ant which were studied in this work (Pons et al. 2010).

Acknowledgments We would like to thank Crisanto Gómez for his help and comments on the manuscript; Oriol Clarabuch for instructing D.E.T on how to measure passerines; Judit Roca, who initiated the preliminary study, Xavier Benito and Maria Lloveras who assisted in the laboratory and in the field, and Francis Boyle who revised the English. The Catalan Institute of Ornithology (ICO) provided ringing permits. The study was funded by the Spanish Ministry of Education and Science (CGL2004-05240-C02-02/BOS and CGL2007-64080-C02-02/ BOS). D.E.T. worked on this project during 2005-2007 with the support of a CUR-DIUE grant (No. 2005FI-00975) from the Catalan Government and the European Social Fund. This study complies with the current laws of Catalonia and Spain, and chick manipulation was carried out under license from ICO.

\section{References}

Abril S, Oliveras J, Gomez C (2007) Foraging activity and dietary spectrum of the Argentine ant (Hymenoptera: Formicidae) in invaded natural areas of the northeast Iberian Peninsula. Environ Entomol 36:1166-1173

Aho T, Kuitunen M, Suhonen J, Jantti A, Hakkari T (1999) Reproductive success of Eurasian Treecreepers, Certhia familiaris, lower in territories with wood ants. Ecology 80:998-1007

Allen AJ, Harper DGC (2000) Foraging Blue Tits Parus caeruleus may trade-off calorific value of food items and distance from cover. Bird Study 47:232-234

Arnold KE, Ramsay SL, Donaldson C, Adam A (2007) Parental prey selection affects risk-taking behaviour and spatial learning in avian offspring. Proc Royal Soc B Biol Sci 274:2563-2569

Arriero E, Fargallo JA (2006) Habitat structure is associated with the expression of carotenoid-based coloration in nestling blue tits Parus caeruleus. Naturwissenschaften 93:173-180

Baayen RH (2010) Language R: data sets and functions with "analyzing linguistic data: a practical introduction to statistics". In: R package version 1.0

Banbura J, Blondel J, Dewildelambrechts H, Galan MJ, Maistre M (1994) Nestling diet variation in an insular Mediterranean population of blue tits Parus caeruleus: effects of years, territories and individuals. Oecologia 100:413-420

Banbura J, Lambrechts MM, Blondel J, Perret P, Cartan-Son M (1999) Food handling time of Blue Tit chicks: constraints and adaptation to different prey types. J Avian Biol 30:263-270

Banbura J, Perret P, Blondel J, Thomas DW, Cartan-Son M, Lambrechts MM (2004) Effects of Protocalliphora parasites on nestling food composition in Corsican blue tits Parus caeruleus: consequences for nestling performance. Acta Ornithol 39:93-103

Bates D, Maechler M (2010) lme4: Linear mixed-effects models using S4 classes. In: R package version 0.999375-35

Bjorklund M (1996) Similarity of growth among great tits (Parus major) and blue tits (P. caeruleus). Biol J Linn Soc 58:343-355

Blem CR (1990) Avian energy storage. In: Power DM (ed) Current ornithology, vol 7. Plenum Press, New York, pp 59-113

Blondel J, Dervieux A, Maistre M, Perret P (1991) Feeding ecology and life-history variation of the Blue Tit in Mediterranean deciduous and sclerophyllous habitats. Oecologia 88:9-14

Blondel J, Maistre M, Perret P, Hurtrez-Bousses S, Lambrechts MM (1998) Is the small clutch size of a Corsican blue tit population optimal? Oecologia 117:80-89

Bond W, Slingsby P (1984) Collapse of an ant-plant mutualism: the Argentine ant (Iridomyrmex humilis) and myrmecochorous Proteaceae. Ecology 65:1031-1037

Bourgault P, Thomas D, Perret P, Blondel J (2010) Spring vegetation phenology is a robust predictor of breeding date across broad landscapes: a multi-site approach using the Corsican blue tit (Cyanistes caeruleus). Oecologia 162:885-892

Carpintero S, Reyes-Lopez J, De Reyna LA (2005) Impact of Argentine ants (Linepithema humile) on an arboreal ant community in Donana National Park, Spain. Biodiv Conserv 14:151-163

Clarke GM (1995) Relationships between developmental stability and fitness - Application for conservation biology. Conserv Biol 9:18-24

Cramp S, Perrins CM (1998) The complete birds of the western paleartic. CD-ROM v. 1.0. Oxford University Press, Oxford

Crawley MJ (2007) The R book. John Wiley and Sons Ltd, Chichester

Eeva T, Helle S, Salminen JP, Hakkarainen H (2010) Carotenoid composition of invertebrates consumed by two insectivorous bird species. J Chem Ecol 36:608-613 
Estany-Tigerström D, Bas JM, Pons P (2010) Does Argentine ant invasion affect prey availability for foliage-gleaning birds? Biol Invas 12:827-839

Figuerola J, Senar JC, Pascual J (1999) The use of a colorimeter in field studies of Blue Tit Parus caeruleus coloration. Ardea 87:269-275

Gandhi KJK, Herms DA (2010) Direct and indirect effects of alien insect herbivores on ecological processes and interactions in forests of eastern North America. Biol Invas 12:389-405

Garcia-Berthou E (2001) On the misuse of residuals in ecology: testing regression residuals vs. the analysis of covariance. J Anim Ecol 70:708-711

Garcia-Navas V, Sanz JJ (2010) Flexibility in the foraging behavior of blue tits in response to short-term manipulations of brood size. Ethology 116:744-754

Garcia-Navas V, Sanz JJ (2011) The importance of a main dish: nestling diet and foraging behaviour in Mediterranean blue tits in relation to prey phenology. Oecologia 165:639-649

Gelman A, Hill J (2007) Data analysis using regression and multilevel/hierarchical models. Cambridge University, Cambridge

Grieco F (2003) Greater food availability reduces tarsus asymmetry in nestling blue tits. Condor 105:599-603

Haemig PD (1999) Predation risk alters interactions among species: competition and facilitation between ants and nesting birds in a boreal forest. Ecol Lett 2:178-184

Halaj J, Wise DH (2001) Terrestrial trophic cascades: how much do they trickle? American Naturalist 157:262-281

Harrison TJE et al (2010) Does food supplementation really enhance productivity of breeding birds? Oecologia 164:311-320

Holway DA, Lach L, Suarez AV, Tsutsui ND, Case TJ (2002) The causes and consequences of ant invasions. Annu Rev Ecol Syst 33:181-233

Hooper-Bui LM, Rust MK, Reierson DA (2004) Predation of the endangered California Least Tern, Sterna antillarum browni by the southern fire ant, Solenopsis xyloni (Hymenoptera, Formicidae). Sociobiology 43:401-418

Human KG, Gordon DM (1997) Effects of Argentine ants on invertebrate biodiversity in northern California. Conserv Biol 11:1242-1248

Hurlbert SH (1984) Pseudoreplication and the design of ecological field experiments. Ecol Monogr 54:187-211

Illera JC, Atienza JC (1995) Foraging shifts by the Blue Tit (Parus caeruleus) in relation to arthropod availability in a mixed woodland during the spring-summer period. Ardeola 42:39-48

Johnsen A, Delhey K, Andersson S, Kempenaers B (2003) Plumage colour in nestling blue tits: sexual dichromatism, condition dependence and genetic effects. Proc Royal Soc B Biol Sci 270:1263-1270

Jones PJ, Ward P (1976) Level of reserve protein as proximate factor controlling timing of breeding and clutch-size in Red-billed quelea Quelea quelea. Ibis 118:547-574

Kenis M et al (2009) Ecological effects of invasive alien insects. Biol Invas 11:21-45

Krause ET, Honarmand M, Wetzel J, Naguib M (2009) Early fasting is long lasting: differences in early nutritional conditions reappear under stressful conditions in adult female zebra finches. Plos One 4
Laakkonen J, Fisher RN, Case TJ (2001) Effect of land cover, habitat fragmentation and ant colonies on the distribution and abundance of shrews in southern California. J Anim Ecol 70:776-788

Laaksonen T, Negro JJ, Lyytinen S, Valkama J, Ots I, Korpimaki E (2008) Effects of experimental brood size manipulation and gender on carotenoid levels of eurasian kestrels Falco tinnunculus. Plos One 3

Lessells CM, Boag PT (1987) Unrepeatable repeatabilities: a common mistake. Auk 104:116-121

Marshall MR, Cooper RJ (2004) Territory size of a migratory songbird in response to caterpillar density and foliage structure. Ecology 85:432-445

Marshall MR, Cooper RJ, DeCecco JA, Strazanac J, Butler L (2002) Effects of experimentally reduced prey abundance on the breeding ecology of the Red-eyed Vireo. Ecol Appl 12:261-280

McGraw KJ, Adkins-Regan E, Parker RS (2005) Maternally derived carotenoid pigments affect offspring survival, sex ratio, and sexual attractiveness in a colorful songbird. Naturwissenschaften 92:375-380

Meijer T, Drent R (1999) Re-examination of the capital and income dichotomy in breeding birds. Ibis 141:399-414

Naef-Daenzer B (2000) Patch time allocation and patch sampling by foraging great and blue tits. Anim Behav 59:989-999

Naef-Daenzer B, Keller LF (1999) The foraging performance of great and blue tits (Parus major and P. caeruleus) in relation to caterpillar development, and its consequences for nestling growth and fledging weight. J Anim Ecol 68:708-718

Naef-Daenzer B, Widmer F, Nuber M (2001) Differential postfledging survival of great and coal tits in relation to their condition and fledging date. J Anim Ecol 70:730-738

Nager RG, Ruegger C, VanNoordwijk AJ (1997) Nutrient or energy limitation on egg formation: a feeding experiment in great tits. J Anim Ecol 66:495-507

Nur N (1984) The consequences of brood size for breeding blue tits.1. Adult survival, weight change and the cost of reproduction. J Anim Ecol 53:479-496

Piñol J, Espadaler X, Canellas N, Martinez-Vilalta J, Barrientos JA, Sol D (2010) Ant versus bird exclusion effects on the arthropod assemblage of an organic citrus grove. Ecol Entomol 35:367-376

Pons P, Bas JM, Estany-Tigerström D (2010) Coping with invasive alien species: the Argentine ant and the insectivorous bird assemblage of Mediterranean oak forests. Biodiv Conserv 19:1711-1723

R Development Core Team (2009) R: A language and environment for statistical computing. In $\mathrm{R}$ foundation for statistical computing. Vienna, Austria

Ramsay SL, Houston DC (1998) The effect of dietary amino acid composition on egg production in blue tits. Proc Royal Soc B Biol Sci 265:1401-1405

Robertson BA, Hutto RL (2006) A framework for understanding ecological traps and an evaluation of existing evidence. Ecology 87:1075-1085

Saks L, McGraw K, Horak P (2003a) How feather colour reflects its carotenoid content. Funct Ecol 17:555-561

Saks L, Ots I, Horak P (2003b) Carotenoid-based plumage coloration of male greenfinches reflects health and immunocompetence. Oecologia 134:301-307 
Schneider KJ (1984) Dominance, predation, and optimal foraging in white-throated sparrow flocks. Ecology 65:1820-1827

Slagsvold T, Lifjeld JT (1985) Variation in plumage color of the great Tit Parus major in relation to habitat, season and food. J Zool 206:321-328

Slotow R, Paxinos E (1997) Intraspecific competition influences food return-predation risk trade-off by white-crowned sparrows. Condor 99:642-650

Stjernman M, Raberg L, Nilsson JA (2008) Long-term effects of nestling condition on blood parasite resistance in blue tits (Cyanistes caeruleus). Can J Zool 86:937-946

Suarez AV, Case TJ (2002) Bottom-up effects on persistence of a specialist predator : ant invasions and horned lizards. Ecol Appl 12:291-298

Suarez AV, Yeh P, Case TJ (2005) Impacts of Argentine ants on avian nesting success. Insectes Soc 52:378-382

Svensson E, Nilsson JA (1995) Food-supply, territory quality, and reproductive timing in the Blue Tit (Parus caeruleus). Ecology 76:1804-1812
Tillberg CV, Holway DA, LeBrun EG, Suarez AV (2007) Trophic ecology of invasive Argentine ants in their native and introduced ranges. Proc Natl Acad Sci USA 104:20856-20861

Tinbergen JM, Vanbalen JH, Vaneck HM (1985) Density dependent survival in an isolated Great Tit populationKluyvers data reanalysed. Ardea 73:38-48

Tremblay I, Thomas D, Blondel J, Perret P, Lambrechts MM (2005) The effect of habitat quality on foraging patterns, provisioning rate and nestling growth in Corsican Blue Tits Parus caeruleus. Ibis 147:17-24

Zandt HS (1997) Water content of prey of nestling blue tits in a Corsican habitat. Neth J Zool 47:125-131

Zuur A, Ieno EN, Saveliev AA, Smith GM (2009) Mixed effects models and extensions in ecology with R. Springer, New York 